\title{
Improving the Detection of Phlebitis in Hospitalized Children
}

\author{
Anshula Tayal ${ }^{1} \cdot$ Rakesh Lodha $^{1}$ \\ Received: 9 February 2021 / Accepted: 10 February 2021 / Published online: 20 February 2021 \\ (C) Dr. K C Chaudhuri Foundation 2021
}

Peripherally inserted venous cannulation (PIVC) is one of the commonest procedures performed in hospitalized children. It is often a lifesaving procedure, enabling administration of various types of intravenous fluids, medications, and blood products. Like any procedure, PIVC is also associated with few complications; important ones include infiltration, extravasation, phlebitis, occlusion, accidental dislodgement, and infection. Phlebitis, i.e., irritation or inflammation of the vessel wall, is a frequent and distressing complication of PIVC.

A recent systematic review on PIVC failure and complications in children estimated the overall pooled incidence of catheter failure to be $38 \%$ and the total incidence of phlebitis to be $5 \%$ [1]. However, much higher rates of $25 \%-50 \%$ have also been reported [2].

Various factors affect the risk of development of phlebitis, including site of placement of PIVC, experience of healthcare worker inserting the device, cannula gauge, cannula materials, etc. [2]. Phlebitis may manifest with a variety of signs and symptoms such as pain, tenderness, swelling, erythema, warmth, leakage, palpable venous cord, and purulent discharge. A study on the incidence of various signs and symptoms of phlebitis found that tenderness was the commonest sign with an incidence of $5.7 \%$, which was more than double that of swelling, and more than three times that of pain [3]. These results highlight the importance of inspection of the cannula site by a healthcare worker, instead of just relying on patient reporting.

Routine changing of PIVC every 72-96 h in the absence of a clinical indication has not been found to reduce the incidence of phlebitis [4]. Accordingly, the present recommendation is rotation of PIVC site based on clinical indications, rather than at preset intervals [5]. Therefore, it is all the more important to routinely inspect the cannula site for any complication. The Infusion Nurses Society has laid down specific recommendations

Rakesh Lodha

rlodha1661@gmail.com

1 Department of Pediatrics, All India Institute of Medical Sciences, New Delhi 110029, India regarding the frequency of assessment of cannula site; for neonatal and pediatric patients, at least hourly assessment is recommended [6].

The recently published study by Robert et al. on the impact of physician inspection in the detection of phlebitis in children admitted to a tertiary care hospital adds to existing knowledge in this area [7]. This was a well-planned study in which thrombophlebitis events were independently recorded by physicians and nurses based on a uniform scoring system. Incidence of phlebitis was found to be $10.3 \%$ and of the total 35 events, $55 \%$ were picked by routine nursing observations, whereas physicians picked up the additional $45 \%$. Additional physician inspection of PIVC almost doubled the detection rate of phlebitis as compared to observation by nurses alone. This increase in the detection rate may be because of increase in number of observations, and not specific to observations by a cadre of healthcare professionals.

Prompt detection of phlebitis and timely corrective measures can save patient discomfort and dissatisfaction to a large extent. Apart from the precautions to be taken during the placement of PIVC, frequent observations by the nursing staff and the doctors to detect phlebitis promptly are important. All cannula sites should be covered with a transparent dressing to allow frequent evaluation. Standard operating procedures should be formulated in all units regarding the frequency of assessment of cannula site.

\section{Declarations}

Conflict of Interest None.

\section{References}

1. Indarwati F, Mathew S, Munday J, Keogh S. Incidence of peripheral intravenous catheter failure and complications in paediatric patients: systematic review and meta analysis. Int J Nurs Stud. 2020;102: 103488

2. Suliman M, Saleh W, Al-shiekh H, Taan W, AlBashtawy M. The incidence of peripheral intravenous catheter phlebitis and risk factors among pediatric patients. J Pediatr Nurs. 2020;50:89-93. 
3. Mihala G, Ray-Barruel G, Chopra V, et al. Phlebitis signs and symptoms with peripheral intravenous catheters. J Infus Nurs. 2018;41:4.

4. Webster J, Osborne S, Rickard CM, Marsh N. Clinically-indicated replacement versus routine replacement of peripheral venous catheters. Cochrane Database Syst Rev [Internet]. 2019;1(1):CD007798 Available at: http://doi.wiley.com/10.1002/14651858.CD007798. pub5. Accessed 25 Jan 2021.

5. Infusion Nurses Society. Infusion nursing standards of practice. J Infus Nurs. 2011;34(1S):S1-110.

6. Gorski LA, Hallock D, Kuehn SC, Morris P, Russell JM, Skala LC. Recommendations for frequency of assessment of the short peripheral catheter site. J Infus Nurs. 2012;35:290-2.
7. Robert M, Jose B, John S. Impact of physician inspection in the detection of phlebitis and factors contributing to it in admitted children of a tertiary care hospital: a prospective study. Indian J Pediatr. 2020. https://doi.org/10.1007/s12098-020-03520-8. Epub ahead of print.

Publisher's Note Springer Nature remains neutral with regard to jurisdictional claims in published maps and institutional affiliations. 